\title{
Kualitas Pelayanan dan Kepuasan Masyarakat pada Kinerja Pegawai Menggunakan Metode Analysis GAP di Kantor Kecamatan Waru Kabupaten Sidoarjo
}

\author{
*Sindy Devi Indriani, Pribadiyono, Enny Istanti \\ Program Studi Manajemen Fakultas Ekonomi dan Bisnis \\ Universitas Bhayangkara Surabaya, Indonesia
}

DOI: $10.46821 /$ benchmark.v1i2.146

\begin{abstract}
Abstrak
Kantor Kecamatan Waru merupakan Suatu lembaga pemerintahan yang memberikan pelayanan kepada masyarakat, apabila layanan yang diberikan sesuai dengan yang diharapakan maka pelayanan tersebut berkualitas, bila tidak maka sebaliknya. Penilaian yang diberikan masyarakat menentukan kinerja pegawai. Tujuan penelian ini adalah untuk mengukur kualitas pelayanan di Kantor Kecamatan Waru Kabupaten Sidoarjo yang dilakukan dengan menggunakan metode Analysis gap. .Analisis kualitas pelayanan atau Service Quality (Servqual) yang meliputi lima dimensi yaitu : Tangibles (Bukti Fisik), Reliability (Kehandalan), Responsiveness (Daya Tanggap), Assurance (Jaminan), dan Empaty (Empati).. Berdasarkan hasil penelitian didapatkan Tangibles (Bukti Fisik) bernilai gap -0.40, Reliability (Kehandalan) bernilai gap -0.31, Responsiveness (Daya Tanggap) bernilai gap -0.35, Assurance (Jaminan) bernilai gap -0.42 dan Empaty (Empati) bernilai gap -0.47. Dalam lima dimensi tersebut perlu adanya peningkatan untuk memenuhi kepuasan masyarakat yaitu penambahan fasilitas toilet umum, pegawai selalu berpakaian seragam dan rapi, pegawai mampu memberikan alur petunjuk sesuai SOP (Prosedur), ketepatan waktu layanan serta pegawai senantiasa menjaga rahasia dokumen pengunjung.
\end{abstract}

Kata kunci: Kualitas Pelayanan, Kepuasan Masyarakat, Analysis GAP

\begin{abstract}
Waru District Office is a government agency that provides services to the community, if the services provided are as expected, the quality of the service, if not vice versa. Assessments given by the community determine employee performance. The purpose of this study is to measure the quality of service in the Waru District Office of Sidoarjo Regency which is carried out using the Analysis gap method. . Analysis of service quality (Service Quality (Servqual) which includes five dimensions, namely: Tangibles (Physical Evidence), Reliability (Reliability), Responsiveness (Responsiveness), Assurance (Assurance), and Empaty (Empathy) .. Based on the research results obtained Tangibles (Physical Evidence) has a gap value of -0.40, Reliability has a gap of 0.31, Responsiveness has a gap of -0.35, Assurance has a gap of - 0.42 and Empaty (Empathy) has a gap of -0.47 . In these five dimensions, there needs to be an increase to meet public satisfaction, namely the addition of public toilet facilities, employees always dress uniformly and neatly, employees are able to provide guidance according to SOP (Procedure), timeliness of service and employees always keep confidential visitor documents.
\end{abstract}

Keywords: Service Quality, Community Satisfaction, GAP Analysis.

*Corresponding Author:

Hal: 85-94

Email: devisindy04@gmail.com 
Sebagaimana dipahami bahwa esensi pemerintahan adalah pelayanan kepada masyarakat oleh karena itu pemerintah tidak diadakan untuk diri sendiri tetapi untuk melayani masyarakat serta menciptakan kondisi yang memungkinkan setiap anggota masyarakat mengembangkan kemampuan dan kreativitasnya demi mencapai tujuan bersama.

Apabila layanan yang diberikan sudah sesuai dengan yang diharapkan oleh masyarakat, maka dapat dikatakan pelayanan tersebut merupakan pelayanan yang berkualitas. Sebaliknya jika layanan yang diberikan tidak sesuai dengan harapan masyarakat, maka dapat dikatakan pelayanan tersebut tidak berkualitas. Tujuan utama pelayanan public adalah kepuasan masyarakat.

Kepuasan ini dapat terwujud apabila pelayanan yang diberikan sesuai dengan standar pelayanan yang ditetapkan atau lebih dari standar tersebut. Pelayanan yang diberikan tanpa memandang status, pangkat, dan golongan dari suatu masyarakat. Pada saat yang sama masyarakat juga mempunyai hak dan kewajiban sebagai warga berbangsa dan bernegara berani mengajukan tuntutan, keinginan dan aspirasinya kepada pemerintah. Penilaian yang diberikan masyarakat menentukan kinerja pelayanan di Kantor Kecamatan Waru.

Kualitas Pelayanan: Menurut Tjiptono dalam Najwa (2019:13) mendefinisikan kualitas pelayanan sebagai salah satu kondisi dinamis yang berhubungan dengan produk, jasa, manusia, proses dan lingkungan yang memenuhi atau melebihi harapan.

Kepuasan : Menurut Tjiptono (2015:23) kepuasan pelanggan adalah perasa senang atau kecewa yang didapatkan seseorang dari membandingkan antara kinerja atau hasil produk yang dipersepsikan dan ekspektasinya.

Kinerja : Menurut Rivai dan Sagala dalam Priansa (2014:269) menyatakan bahwa kinerja adalah perilaku yang nyata yang ditampilkan setiap orang sebagai prestasi kerja yang dihasilkan oleh pegawai sesuai dengan perannya dalam organisasi.

\section{METODE PENELITIAN}

Penelitian ini merupakan penelitian deskriptif kualitatif. Dengan menggunakan kuesioner kepada masyarakat yang menggunakan pelayanan jasa di Kantor Kecamatan Waru Sidoarjo, kemudian dianalisis dengan metode Analysis GAP.

\section{Jenis Data}

a. Data Primer yaitu data yang diperoleh langsung dari sumbernya dalam hal ini menggunakan data, hasil observasi dan kuesioner dari Kantor Kecamatan Waru Kabupaten Sidoarjo.

b. Data Sekunder yaitu data yang diperoleh dari luar instansi yang di peroleh secara tidak langsung melalui buku, literatur, majalah ataupun media lain.

\section{Pengujian Data}

Pengujian data adalah alat atau fasilitas yang digunakan oleh peneliti dalam mengumpulkan data agar penelitiannya lebih sistematis sehingga lebih mudah diolah. Pengujian data digunakan oleh peneliti pada saat pengumpulan data sesuai dengan teknik pengumpulan data yang sudah ditentukan. 


\section{Tabel 1}

Kisi-kisi Observasi di Kantor Kecamatan Waru

\begin{tabular}{|c|c|c|}
\hline No & Indikator & Keterangan \\
\hline 1 & Tangibles/Bukti Nyata & $\begin{array}{l}\text { 1. Lokasi dan lahan kecamatan sudah memenuhi syarat } \\
\text { 2. Lokasi parkir sudah memenuhi syarat } \\
\text { 3. Ruang pelayanan yang standart } \\
\text { 4. Ruang tertata baik } \\
\text { 5. Ada papan informasi, TV, Majalah } \\
\text { 6. Semua ruangan terasa nyaman dan ber AC } \\
\text { 7. Terdapat fasilitas toilet dikantor } \\
\text { 8. Terdapat area smoking } \\
\text { 9. Pelayanan disupport IT } \\
\text { 10. Fasilitas penunjang pelayanan seperti komputer, printer } \\
\text { dll } \\
\text { 11. Ruang tunggu dengan tempat duduk yang cukup }\end{array}$ \\
\hline 2 & Reability/Keterandalan & $\begin{array}{l}\text { 1. Pegawai front office berkompeten dalam layanan } \\
\text { 2. Seluruh pegawai bekerja dengan handal } \\
\text { 3. Mengarahkan dalam pelayanan } \\
\text { 4. Pegawai mudah memberi informasi } \\
\text { 5. Pegawai mencukupi dalam pelayanan } \\
\text { 6. Pelayanan sesuai kedatangan antrean } \\
\text { 7. Pegawai berseragam dan rapi }\end{array}$ \\
\hline 3 & $\begin{array}{l}\text { Responsiveness/Daya } \\
\text { Tanggap }\end{array}$ & $\begin{array}{l}\text { 1. Pegawai dapat memberi informasi yang mudah dipahami } \\
\text { 2. Pegawai bertanggung jawab } \\
\text { 3. Pegawai yang bersahabat } \\
\text { 4. Pegawai memberi kesempatan bertanya dan mudah } \\
\text { memberikan jawaban } \\
\text { 5. Pegawai memberikan alur petunjuk layanan sesuai SOP } \\
\text { (prosedur) } \\
\text { 6. Pegawai ramah dan sabar } \\
\text { 7. Pegawai bekerja dengan cekatan }\end{array}$ \\
\hline 4 & Assurance/Jaminan & $\begin{array}{l}\text { 1. Pegawai sopan dalam pemanggilan pengunjung } \\
\text { 2. Ketepatan pelayanan (waktu yang tepat) } \\
\text { 3. Pegawai tidak bertele-tele } \\
\text { 4. Tidak ada pungutan liar } \\
\text { 5. Kejujuran pegawai } \\
\text { 6. Kecepatan proses pelayanan } \\
\text { 7. Ketepatan waktu pelayanan } \\
\text { 8. Tidak berbuat kesalahan dalam tanggung jawab } \\
\text { pelayanan administrasi dan KTP }\end{array}$ \\
\hline 5 & Empaty/Empati & $\begin{array}{l}\text { 1. Pegawai berkomunikasi dengan sopan } \\
\text { 2. Pegawai membantu dengan ikhlas dan sabar } \\
\text { 3. Kepedulian layanan } \\
\text { 4. Memahami kebutuhan administrasi } \\
\text { 5. Adanya sarana pendampingan dari pegawai } \\
\text { 6. Menjaga rahasia dokumen pengunjung }\end{array}$ \\
\hline
\end{tabular}

Sumber: Data Diolah, 2020 
HASIL ANALISIS DAN PEMBAHASAN

Analysis $G A P$

Analysis gap merupakan analisis yang dilihat berdasarkan tingkat kesesuaian antara jasa yang diharapkan (kepentingan pengunjung) dengan jasa yang dirasakan (kinerja pegawai). Tingkat kesesuaian yang dimaksud dalam pelaksanaan penelitian adalah hasil perbandingan skor nilai pelayanan yang diharapkan (kepentingan pengunjung) dengan skor nilai yang dirasakan (kinerja pegawai).

\section{Improvement Ratio (IR) dan Costumer Statisfaction Index (CSI)}

Untuk mengetahui Index Upaya Perbaikan dalam kualitas pelayanan dan kepuasan masyarakat di Kantor Kecamatan Waru Kabupaten Sidoarjo

Dari hasil analisa dapat dijelaskan bahwa terdapat lima dimensi yang disimpulkan sebagai berikut :

a. Tangibles

Dimensi ini merupakan tanggapan pengunjung terhadap fasilitas fisik yang ada di Kantor Kecamatan Waru seperti peralatan, perlengkapan dan fasilitas IT. Secara rata-rata nilai gap yang terjadi antara harapan dan kenyataan sebesar $3.75-3.35=(-$ 0.40). dari dimensi ini item yang memiliki gap paling kecil atau tingkat kepuasan terbesar adalah item no.11 (0.24) yaitu ruang tunggu tempat duduk yang cukup. Sedangkan item yang memiliki gap paling besar atau tingkat kepuasan terkecil no. 6 $(-0.74)$ yaitu Semua ruangan berasa nyaman dan berAC. kualitas pelayanan pada dimensi ini belum sesuai harapan, oleh karena itu diharapkan pegawai perlu mempercantik ruangan agar suasana terlihat nyaman dan dengan memperbaiki AC atau menambah alat operasional AC untuk ruangan tersebut dingin sehingga pengunjung merasa terpuaskan.

b. Reliability

Dimensi ini merupakan tanggapan pengunjung terhadap keandalan kinerja di Kantor Kecamatan Waru dalam hal akurasi dan pelayanan yang sesuai sehingga memuaskan para pengunjung. Secara rata-rata gap yang terjadi antara harapan dan kenyataan sebesar $3.79-3.48=(-0.31)$. dari dimensi ini item yang memiliki gap paling kecil atau tingkat kepuasan terbesar adalah item no. 2 dan 6 (-0.24) yaitu seluruh pegawai bekerja dengan handal dan pelayanan sesuai kedatangan antrean. Sedangkan item yang memiliki gap paling besar atau tingkat kepuasan terkecil no. 7 (-0.52) yaitu Pegawai berseragam dan rapi, kualitas pelayanan pada dimensi ini belum sesuai harapan sepenuhnya, untuk itu diharapkan pegawai perlu meningkatkan lagi agar dimensi keterandalan dapat memenuhi harapan pengunjung.

c. Responsiveness

Dimensi ini merupakan tanggapan pengunjung terhadap Kesediaan para pegawai memberikan pelayanan secara tanggap di Kantor Kecamatan Waru. Secara rata-rata gap yang terjadi antara harapan dan kenyataan sebesar $3.89-3.54=(-0.35)$. dari dimensi ini item yang memiliki gap paling kecil atau tingkat kepuasan terbesar adalah item no. 7 (0.62) yaitu Pegawai bekerja cekatan. Sedangkan item yang memiliki gap paling besar atau tingkat kepuasan terkecil no. 5 (-1.00) yaitu Pegawai memberikan alur petunjuk layanan seperti SOP (prosedur). kualitas pelayanan pada 
dimensi ini belum sesuai harapan, untuk itu pegawai diharapkan agar meningkatkan kinerjanya sesuai dengan SOP yang ada di Kantor Kecamatan Waru.

d. Assurance

Dimensi ini merupakan tanggapan pengunjung terhadap kesediaan pegawai di Kantor Kecamatan Waru dalam memberikan pelayanan kepada pengunjung yang membutuhkan. Secara rata-rata gap yang terjadi antara harapan dan kenyataan sebesar $3.91-3.49=(-0.42)$. dari dimensi ini item yang memiliki gap paling kecil atau tingkat kepuasan terbesar adalah item no. $3(-0.26)$ yaitu pegawai tidak berteletele. Sedangkan item yang memiliki gap paling besar atau tingkat kepuasan terkecil no. 6 (-0.58) yaitu Kecepatan proses pelayanan. kualitas pelayanan pada dimensi ini belum sesuai harapan, untuk itu diharapkan pegawai perlu mengefektifkan waktu melayani pengunjung.

e. Emphaty

Dimensi ini merupakan tanggapan pengunjung perhatian secara personal yang diberikan oleh pegawai yang ada di Kantor Kecamatan Waru. Secara rata-rata gap yang terjadi antara harapan dan kenyataan sebesar $3.95-3.48=(-0.47)$. dari dimensi ini item yang memiliki gap paling kecil atau tingkat kepuasan terbesar adalah item no.1 dan 5 (-0.38) yaitu pegawai berkomunikasi dengan sopan dan adanya sarana pendampingan dari pegawai. Sedangkan item yang memiliki gap paling besar atau tingkat kepuasan terkecil no. 6 (-0.66) yaitu menjaga rahasia dokumen pengunjung. kualitas pelayanan pada dimensi ini belum sesuai harapan, dihimbau untuk pegawai agar selalu menjaga privasi dokumen pengunjung karena merupakan hak pengunjung.

\section{SIMPULAN DAN SARAN}

Dari pembahasan kualitas pelayanan di Kantor Kecamatan Waru Kabupaten Sidoarjo dengan menggunakan metode analisis gap dapat disimpulkan sebagai berikut. Berdasarkan perhitungan metode servqual didapatkan dimensi tangibles bernilai gap -0.40 , dimensi reliability bernilai gap -0.31, dimensi responsiveness bernilai gap -0.35, dan dimensi emphaty bernilai gap -0.47. Dari hasil tersebut menunjukkan kelima dimensi seluruhnya bernilai gap negatif maka dapat disimpulkan bahwa para pengunjung belum merasa puas terhadap pelayanan yang diberikan oleh Kantor Kecamatan Waru Kabupaten Sidoarjo. Dalam 5 dimensi tersebut perlu adanya peningkatan untuk memenuhi kepuasan pengunjung di Kantor Kecamatan Waru adalah penambahan AC atau memperbaikinya, pegawai selalu berpakaian seragam dan rapi, pegawai mampu memberikan alur petunjuk sesuai SOP (Prosedur), ketepatan waktu layanan serta pegawai senantiasa menjaga rahasia dokumen pengunjung. Adapun saran yang dapat diberikan pada peneliti selanjutnya adalah sebagai berikut: Penelitian ini memiliki keterbatasan diantaranya penelitian hanya dilakukan pada Kualitas Layanan pada Kantor Kecamatan Waru Kabupaten Sidoarjo. Sehingga perlu dilakukan penelitian lebih jauh terhadap perkantoran penyedia jasa lainnya dan mengenai pola perilaku pengunjung terhadap keinginan pemenuhan kepuasan dalam pelayanan. Untuk strategi perbaikannya para pegawai Kantor Kecamatan Waru Kabupaten Sidoarjo diharapkan lebih mengefektifkan dan mengefesiensikan dalam hal pelayanan supaya masyarakat yang datang untuk menggunakan jasa di Kantor Kecamatan Waru merasa 
terpuaskan. Untuk strategi perbaikannya para pegawai Kantor Kecamatan Waru Kabupaten Sidoarjo diharapkan lebih mengefektifkan dan mengefesiensikan dalam hal pelayanan supaya masyarakat yang datang untuk menggunakan jasa di Kantor Kecamatan Waru merasa terpuaskan. Menambah metode lain seperti Importance Performance Analysis (IPA) atau yang lainnya.

\section{DAFTAR PUSTAKA}

Najma, N. E. 2019, Analisis Pengaruh Kualitas Layanan, Kepuasan, dan Kepercayaan terhadap Loyalitas Pelanggan di PT Warnatama Cemerlang Gresik, Skripsi. Fakultas Ekonomi dan Bisnis Universitas Bhayangkara Surabaya.

Priansa, D. J. (2014). Perencanaan dan Pengembangan Sumber Daya Manusia. Bandung: Alfabeta.

Tjiptono, Fandy, \& Diana, A. (2015). Pelanggan Puas?, Tak Cukup. Yogyakarta: Andi. 


\begin{tabular}{|c|c|c|c|c|c|}
\hline No & ATRIBUT & Harapan & Kenyataan & $\sum_{\text {GAP }}$ & PENILAIAN \\
\hline $\mathrm{A}$ & Tangibles & & & & \\
\hline 1 & $\begin{array}{l}\text { Lokasi dan Lahan kecamatan } \\
\text { sudah memenuhi syarat }\end{array}$ & 3.88 & 3.36 & -0.52 & $\begin{array}{l}\text { TSH (TIDAK SESUAI } \\
\text { HARAPAN) }\end{array}$ \\
\hline 2 & $\begin{array}{l}\text { Lokasi parkir sudah memenuhi } \\
\text { syarat }\end{array}$ & 3.68 & 3.32 & -0.36 & $\begin{array}{l}\text { TSH (TIDAK SESUAI } \\
\text { HARAPAN) }\end{array}$ \\
\hline 3 & Ruang pelayanan yang standart & 3.74 & 3.32 & -0.42 & $\begin{array}{l}\text { TSH (TIDAK SESUAI } \\
\text { HARAPAN) }\end{array}$ \\
\hline 4 & Ruang tata baik & 3.88 & 3.34 & -0.54 & $\begin{array}{l}\text { TSH (TIDAK SESUAI } \\
\text { HARAPAN) }\end{array}$ \\
\hline 5 & $\begin{array}{l}\text { Ada papan informasi, TV, } \\
\text { Majalah }\end{array}$ & 3.88 & 3.2 & -0.68 & $\begin{array}{l}\text { TSH (TIDAK SESUAI } \\
\text { HARAPAN) }\end{array}$ \\
\hline 6 & $\begin{array}{l}\text { Semua ruangan terasa nyaman } \\
\text { dan berAC }\end{array}$ & 3.88 & 3.14 & -0.74 & $\begin{array}{l}\text { TSH (TIDAK SESUAI } \\
\text { HARAPAN) }\end{array}$ \\
\hline 7 & Terdapat Fasilitas toilet dikantor & 3.72 & 3.38 & -0.34 & $\begin{array}{l}\text { TSH (TIDAK SESUAI } \\
\text { HARAPAN) }\end{array}$ \\
\hline 8 & Terdapat area smoking & 3.74 & 3.16 & -0.58 & $\begin{array}{l}\text { TSH (TIDAK SESUAI } \\
\text { HARAPAN) }\end{array}$ \\
\hline 9 & Pelayanan di support IT & 3.94 & 3.52 & -0.42 & $\begin{array}{l}\text { TSH (TIDAK SESUAI } \\
\text { HARAPAN) }\end{array}$ \\
\hline 10 & $\begin{array}{l}\text { Fasilitas Penunjang pelayanan } \\
\text { seperti komputer, printer dll }\end{array}$ & 3.64 & 3.64 & 0 & $\begin{array}{l}\text { SP (SESUAI } \\
\text { HARAPAN) }\end{array}$ \\
\hline 11 & $\begin{array}{l}\text { Ruang tunggu dengan Tempat } \\
\text { duduk yang cukup }\end{array}$ & 3.28 & 3.52 & 0.24 & $\begin{array}{l}\text { SSH (SANGAT SESUAI } \\
\text { HARAPAN) }\end{array}$ \\
\hline$\sum$ & Rata-rata Total & 3.75 & 3.35 & -0.40 & $\begin{array}{l}\text { TSH (TIDAK SESUAI } \\
\text { HARAPAN) }\end{array}$ \\
\hline $\mathrm{B}$ & Reliability & & & & \\
\hline 1 & $\begin{array}{l}\text { Pegawai Front Office } \\
\text { berkompeten dalam layanan }\end{array}$ & 3.88 & 3.6 & -0.28 & $\begin{array}{l}\text { TSH (TIDAK SESUAI } \\
\text { HARAPAN) }\end{array}$ \\
\hline 2 & $\begin{array}{l}\text { Seluruh pegawai bekerja dengan } \\
\text { handal }\end{array}$ & 3.78 & 3.54 & -0.24 & $\begin{array}{l}\text { TSH (TIDAK SESUAI } \\
\text { HARAPAN) }\end{array}$ \\
\hline 3 & mengarahkan dalam pelayanan & 3.92 & 3.66 & -0.26 & $\begin{array}{l}\text { TSH (TIDAK SESUAI } \\
\text { HARAPAN) }\end{array}$ \\
\hline 4 & $\begin{array}{l}\text { Pegawai mudah memberi } \\
\text { informasi }\end{array}$ & 3.84 & 3.48 & -0.36 & $\begin{array}{l}\text { TSH (TIDAK SESUAI } \\
\text { HARAPAN) }\end{array}$ \\
\hline 5 & $\begin{array}{l}\text { Pegawai mencukupi dalam } \\
\text { pelayanan }\end{array}$ & 3.68 & 3.38 & -0.3 & $\begin{array}{l}\text { TSH (TIDAK SESUAI } \\
\text { HARAPAN) }\end{array}$ \\
\hline 6 & $\begin{array}{l}\text { Pelayanan sesuai kedatangan } \\
\text { antrean }\end{array}$ & 3.64 & 3.4 & -0.24 & $\begin{array}{l}\text { TSH (TIDAK SESUAI } \\
\text { HARAPAN) }\end{array}$ \\
\hline 7 & Pegawai berseragam dan rapi & 3.82 & 3.3 & -0.52 & $\begin{array}{l}\text { TSH (TIDAK SESUAI } \\
\text { HARAPAN) }\end{array}$ \\
\hline$\Sigma$ & Rata-rata Total & 3.79 & 3.48 & -0.31 & $\begin{array}{l}\text { TSH (TIDAK SESUAI } \\
\text { HARAPAN) }\end{array}$ \\
\hline $\mathrm{C}$ & Responsivenesss & & & & \\
\hline 1 & $\begin{array}{l}\text { Pegawai dapat memberi } \\
\text { informasi yang mudah dipahami }\end{array}$ & 3.72 & 3.62 & -0.1 & $\begin{array}{l}\text { TSH (TIDAK SESUAI } \\
\text { HARAPAN) }\end{array}$ \\
\hline 2 & Pegawai bertanggung jawab & 3.76 & 3.38 & -0.38 & $\begin{array}{l}\text { TSH (TIDAK SESUAI } \\
\text { HARAPAN) }\end{array}$ \\
\hline 3 & Pegawai bersahabat & 3.88 & 3.3 & -0.58 & $\begin{array}{l}\text { TSH (TIDAK SESUAI } \\
\text { HARAPAN) }\end{array}$ \\
\hline 4 & $\begin{array}{l}\text { Pegawai memberi kesempatan } \\
\text { bertanya dan mudah }\end{array}$ & 3.96 & 3.32 & -0.64 & $\begin{array}{l}\text { TSH (TIDAK SESUAI } \\
\text { HARAPAN) }\end{array}$ \\
\hline
\end{tabular}




\begin{tabular}{|c|c|c|c|c|c|}
\hline No & ATRIBUT & Harapan & Kenyataan & $\sum_{\text {GAP }}$ & PENILAIAN \\
\hline 5 & $\begin{array}{l}\text { memberikan jawaban } \\
\text { Pegawai memberikan alur } \\
\text { petunjuk layanan sesuai SOP } \\
\text { (Prosedur) }\end{array}$ & 4.16 & 3.16 & -1 & $\begin{array}{l}\text { TSH (TIDAK SESUAI } \\
\text { HARAPAN) }\end{array}$ \\
\hline 6 & Pegawai ramah dan sabar & 3.86 & 3.5 & -0.36 & $\begin{array}{l}\text { TSH (TIDAK SESUAI } \\
\text { HARAPAN) }\end{array}$ \\
\hline 7 & Pegawai bekerja dengan cekatan & 3.86 & 4.48 & 0.62 & $\begin{array}{l}\text { SSH (SANGAT SESUAI } \\
\text { HARAPAN) }\end{array}$ \\
\hline$\sum$ & Rata-rata Total & 3.89 & 3.54 & -0.35 & $\begin{array}{l}\text { TSH (TIDAK SESUAI } \\
\text { HARAPAN) }\end{array}$ \\
\hline $\mathrm{D}$ & Assurance & & & & \\
\hline 1 & $\begin{array}{l}\text { Pegawai sopan dalam } \\
\text { pemanggilan pengunjung }\end{array}$ & 4 & 3.72 & -0.28 & $\begin{array}{l}\text { TSH (TIDAK SESUAI } \\
\text { HARAPAN) }\end{array}$ \\
\hline 2 & $\begin{array}{l}\text { Ketepatan Pelayanan (Waktu } \\
\text { yang tepat) }\end{array}$ & 3.9 & 3.5 & -0.4 & $\begin{array}{l}\text { TSH (TIDAK SESUAI } \\
\text { HARAPAN) }\end{array}$ \\
\hline 3 & Pegawai tidak bertele-tele & 3.8 & 3.54 & -0.26 & $\begin{array}{l}\text { TSH (TIDAK SESUAI } \\
\text { HARAPAN) }\end{array}$ \\
\hline 4 & Tidak ada pungutan liar & 3.8 & 3.38 & -0.42 & $\begin{array}{l}\text { TSH (TIDAK SESUAI } \\
\text { HARAPAN) }\end{array}$ \\
\hline 5 & Kejujuran Pegawai & 3.9 & 3.44 & -0.46 & $\begin{array}{l}\text { TSH (TIDAK SESUAI } \\
\text { HARAPAN) }\end{array}$ \\
\hline 6 & Kecepatan proses pelayanan & 3.98 & 3.4 & -0.58 & $\begin{array}{l}\text { TSH (TIDAK SESUAI } \\
\text { HARAPAN) }\end{array}$ \\
\hline 7 & Ketepatan waktu Pelayanan & 3.86 & 3.38 & -0.48 & $\begin{array}{l}\text { TSH (TIDAK SESUAI } \\
\text { HARAPAN) }\end{array}$ \\
\hline 8 & $\begin{array}{l}\text { Tidak berbuat kesalahan dalam } \\
\text { tanggung jawab pelayanan } \\
\text { administrasi dan KTP }\end{array}$ & 4.02 & 3.58 & -0.44 & $\begin{array}{l}\text { TSH (TIDAK SESUAI } \\
\text { HARAPAN) }\end{array}$ \\
\hline$\sum$ & Rata-rata Total & 3.91 & 3.49 & -0.42 & $\begin{array}{l}\text { TSH (TIDAK SESUAI } \\
\text { HARAPAN) }\end{array}$ \\
\hline $\mathrm{E}$ & Emphaty & & & & \\
\hline 1 & $\begin{array}{l}\text { Pegawai berkomunikasi dengan } \\
\text { sopan }\end{array}$ & 3.92 & 3.54 & -0.38 & $\begin{array}{l}\text { TSH (TIDAK SESUAI } \\
\text { HARAPAN) }\end{array}$ \\
\hline 2 & $\begin{array}{l}\text { Pegawai membantu dengan } \\
\text { ikhlas dan sabar }\end{array}$ & 3.84 & 3.44 & -0.4 & $\begin{array}{l}\text { TSH (TIDAK SESUAI } \\
\text { HARAPAN) }\end{array}$ \\
\hline 3 & Kepedulian layanan & 4.06 & 3.56 & -0.5 & $\begin{array}{l}\text { TSH (TIDAK SESUAI } \\
\text { HARAPAN) }\end{array}$ \\
\hline 4 & $\begin{array}{l}\text { Memahami kebutuhan } \\
\text { administrasi }\end{array}$ & 3.98 & 3.52 & -0.46 & $\begin{array}{l}\text { TSH (TIDAK SESUAI } \\
\text { HARAPAN) }\end{array}$ \\
\hline 5 & $\begin{array}{l}\text { Adanya sarana pendampingan } \\
\text { dari pegawai }\end{array}$ & 3.82 & 3.44 & -0.38 & $\begin{array}{l}\text { TSH (TIDAK SESUAI } \\
\text { HARAPAN) }\end{array}$ \\
\hline 6 & $\begin{array}{l}\text { Menjaga rahasia dokumen } \\
\text { pengunjung }\end{array}$ & 4.06 & 3.4 & -0.66 & $\begin{array}{l}\text { TSH (TIDAK SESUAI } \\
\text { HARAPAN) }\end{array}$ \\
\hline$\sum$ & Rata-rata Total & 3.95 & 3.48 & -0.47 & $\begin{array}{l}\text { TSH (TIDAK SESUAI } \\
\text { HARAPAN) }\end{array}$ \\
\hline
\end{tabular}

Sumber: Data Diolah, 2020 
Lampiran 2. Improvement Ratio (IR) dan Costumer Satisfaction Index (CSI)

\begin{tabular}{|c|c|c|c|c|c|c|}
\hline A & Tangibles & Harapan & Kenyataan & IR & CSI & Penilaian \\
\hline 1 & $\begin{array}{l}\text { Lokasi dan Lahan kecamatan } \\
\text { sudah memenuhi syarat }\end{array}$ & 3.88 & 3.36 & 1.15 & $87 \%$ & $\begin{array}{l}\text { Bagus / Kurang } \\
\text { Puas }\end{array}$ \\
\hline 2 & $\begin{array}{l}\text { Lokasi parkir sudah memenuhi } \\
\text { syarat }\end{array}$ & 3.68 & 3.32 & 1.11 & $90 \%$ & $\begin{array}{l}\text { Bagus / Kurang } \\
\text { Puas }\end{array}$ \\
\hline 3 & Ruang pelayanan yang standart & 3.74 & 3.32 & 1.13 & $89 \%$ & $\begin{array}{l}\text { Bagus / Kurang } \\
\text { Puas }\end{array}$ \\
\hline 4 & Ruang tata baik & 3.88 & 3.34 & 1.16 & $86 \%$ & $\begin{array}{l}\text { Bagus / Kurang } \\
\text { Puas }\end{array}$ \\
\hline 5 & $\begin{array}{l}\text { Ada papan informasi, TV, } \\
\text { Majalah }\end{array}$ & 3.88 & 3.2 & 1.21 & $82 \%$ & $\begin{array}{l}\text { Bagus / Kurang } \\
\text { Puas }\end{array}$ \\
\hline 6 & $\begin{array}{l}\text { Semua ruangan terasa nyaman } \\
\text { dan berAC }\end{array}$ & 3.88 & 3.14 & 1.24 & $81 \%$ & $\begin{array}{l}\text { Bagus / Kurang } \\
\text { Puas }\end{array}$ \\
\hline 7 & Terdapat Fasilitas toilet dikantor & 3.72 & 3.38 & 1.10 & $91 \%$ & Bagus / Puas \\
\hline 8 & Terdapat area smoking & 3.74 & 3.16 & 1.18 & $84 \%$ & $\begin{array}{l}\text { Bagus / Kurang } \\
\text { Puas }\end{array}$ \\
\hline 9 & Pelayanan di support IT & 3.94 & 3.52 & 1.12 & $89 \%$ & $\begin{array}{l}\text { Bagus / Kurang } \\
\text { Puas }\end{array}$ \\
\hline 10 & $\begin{array}{l}\text { Fasilitas Penunjang pelayanan } \\
\text { seperti komputer, printer dll }\end{array}$ & 3.64 & 3.64 & 1.00 & $100 \%$ & $\begin{array}{l}\text { Sangat Bagus / } \\
\text { Puas }\end{array}$ \\
\hline 11 & $\begin{array}{l}\text { Ruang tunggu dengan Tempat } \\
\text { duduk yang cukup }\end{array}$ & 3.28 & 3.52 & 0.93 & $107 \%$ & $\begin{array}{l}\text { Sangat Bagus / } \\
\text { Sangat Puas } \\
\text { Sekali }\end{array}$ \\
\hline $\mathrm{B}$ & Reability & & & & & \\
\hline 1 & $\begin{array}{l}\text { Pegawai Front Office } \\
\text { berkompeten dalam layanan }\end{array}$ & 3.88 & 3.6 & 1.08 & $93 \%$ & Bagus / Puas \\
\hline 2 & $\begin{array}{l}\text { Seluruh pegawai bekerja dengan } \\
\text { handal }\end{array}$ & 3.78 & 3.54 & 1.07 & $94 \%$ & Bagus / Puas \\
\hline 3 & mengarahkan dalam pelayanan & 3.92 & 3.66 & 1.07 & $93 \%$ & Bagus / Puas \\
\hline 4 & $\begin{array}{l}\text { Pegawai mudah memberi } \\
\text { informasi }\end{array}$ & 3.84 & 3.48 & 1.10 & $91 \%$ & Bagus / Puas \\
\hline 5 & $\begin{array}{l}\text { Pegawai mencukupi dalam } \\
\text { pelayanan }\end{array}$ & 3.68 & 3.38 & 1.09 & $92 \%$ & Bagus / Puas \\
\hline 6 & $\begin{array}{l}\text { Pelayanan sesuai kedatangan } \\
\text { antrean }\end{array}$ & 3.64 & 3.4 & 1.07 & $93 \%$ & Bagus / Puas \\
\hline 7 & Pegawai berseragam dan rapi & 3.82 & 3.3 & 1.16 & $86 \%$ & $\begin{array}{l}\text { Bagus / Kurang } \\
\text { Puas }\end{array}$ \\
\hline $\mathrm{C}$ & Responsivenesss & & & & & \\
\hline 1 & $\begin{array}{l}\text { Pegawai dapat memberi } \\
\text { informasi yang mudah dipahami }\end{array}$ & 3.72 & 3.62 & 1.03 & $97 \%$ & Bagus / Puas \\
\hline 2 & Pegawai bertanggung jawab & 3.76 & 3.38 & 1.11 & $90 \%$ & Bagus / Puas \\
\hline 3 & Pegawai bersahabat & 3.88 & 3.3 & 1.18 & $85 \%$ & $\begin{array}{l}\text { Bagus / Kurang } \\
\text { Puas }\end{array}$ \\
\hline 4 & $\begin{array}{l}\text { Pegawai memberi kesempatan } \\
\text { bertanya dan mudah memberikan } \\
\text { jawaban }\end{array}$ & 3.96 & 3.32 & 1.19 & $84 \%$ & $\begin{array}{l}\text { Bagus / Kurang } \\
\text { Puas }\end{array}$ \\
\hline 5 & $\begin{array}{l}\text { Pegawai memberikan alur } \\
\text { petunjuk layanan sesuai SOP } \\
\text { (Prosedur) }\end{array}$ & 4.16 & 3.16 & 1.32 & $76 \%$ & $\begin{array}{l}\text { Kurang Bagus / } \\
\text { Tidak Puas }\end{array}$ \\
\hline 6 & Pegawai ramah dan sabar & 3.86 & 3.5 & 1.10 & $91 \%$ & Bagus / Puas \\
\hline 7 & Pegawai bekerja dengan cekatan & 3.86 & 4.48 & 0.86 & $116 \%$ & $\begin{array}{l}\text { Sangat Bagus / } \\
\text { Sangat Puas }\end{array}$ \\
\hline
\end{tabular}


Sindy D Indriani dkk., Kinerja Pengawai Menggunakan Metode Analysis Gap

Bhencmark

\begin{tabular}{|c|c|c|c|c|c|c|}
\hline A & Tangibles & Harapan & Kenyataan & IR & CSI & Penilaian \\
\hline & & & & & & Sekali \\
\hline $\mathrm{D}$ & Assurance & & & & & \\
\hline 1 & $\begin{array}{l}\text { Pegawai sopan dalam } \\
\text { pemanggilan pengunjung }\end{array}$ & 4 & 3.72 & 1.08 & $93 \%$ & Bagus / Puas \\
\hline 2 & $\begin{array}{l}\text { Ketepatan Pelayanan (Waktu } \\
\text { yang tepat) }\end{array}$ & 3.9 & 3.5 & 1.11 & $90 \%$ & Bagus / Puas \\
\hline 3 & Pegawai tidak bertele-tele & 3.8 & 3.54 & 1.07 & $93 \%$ & Bagus / Puas \\
\hline 4 & Tidak ada pungutan liar & 3.8 & 3.38 & 1.12 & $89 \%$ & $\begin{array}{l}\text { Bagus / Kurang } \\
\text { Puas }\end{array}$ \\
\hline 5 & Kejujuran Pegawai & 3.9 & 3.44 & 1.13 & $88 \%$ & $\begin{array}{l}\text { Bagus / Kurang } \\
\text { Puas }\end{array}$ \\
\hline 6 & Kecepatan proses pelayanan & 3.98 & 3.4 & 1.17 & $85 \%$ & $\begin{array}{l}\text { Bagus / Kurang } \\
\text { Puas }\end{array}$ \\
\hline 7 & Ketepatan waktu Pelayanan & 3.86 & 3.38 & 1.14 & $88 \%$ & $\begin{array}{l}\text { Bagus / Kurang } \\
\text { Puas }\end{array}$ \\
\hline 8 & $\begin{array}{l}\text { Tidak berbuat kesalahan dalam } \\
\text { tanggung jawab pelayanan } \\
\text { administrasi dan KTP }\end{array}$ & 4.02 & 3.58 & 1.12 & $89 \%$ & $\begin{array}{l}\text { Bagus / Kurang } \\
\text { Puas }\end{array}$ \\
\hline $\mathrm{E}$ & Empaty & & & & & \\
\hline 1 & $\begin{array}{l}\text { Pegawai berkomunikasi dengan } \\
\text { sopan }\end{array}$ & 3.92 & 3.54 & 1.11 & $90 \%$ & $\begin{array}{l}\text { Bagus / Kurang } \\
\text { Puas }\end{array}$ \\
\hline 2 & $\begin{array}{l}\text { Pegawai membantu dengan } \\
\text { ikhlas dan sabar }\end{array}$ & 3.84 & 3.44 & 1.12 & $90 \%$ & $\begin{array}{l}\text { Bagus / Kurang } \\
\text { Puas }\end{array}$ \\
\hline 3 & Kepedulian layanan & 4.06 & 3.56 & 1.14 & $88 \%$ & $\begin{array}{l}\text { Bagus / Kurang } \\
\text { Puas }\end{array}$ \\
\hline 4 & $\begin{array}{l}\text { Memahami kebutuhan } \\
\text { administrasi }\end{array}$ & 3.98 & 3.52 & 1.13 & $88 \%$ & $\begin{array}{l}\text { Bagus / Kurang } \\
\text { Puas }\end{array}$ \\
\hline 5 & $\begin{array}{l}\text { Adanya sarana pendampingan } \\
\text { dari pegawai }\end{array}$ & 3.82 & 3.44 & 1.11 & $90 \%$ & $\begin{array}{l}\text { Bagus / Kurang } \\
\text { Puas }\end{array}$ \\
\hline 6 & $\begin{array}{l}\text { Menjaga rahasia dokumen } \\
\text { pengunjung }\end{array}$ & 4.06 & 3.4 & 1.19 & $84 \%$ & $\begin{array}{l}\text { Bagus / Kurang } \\
\text { Puas }\end{array}$ \\
\hline
\end{tabular}

Sumber: Data Diolah, 2020 